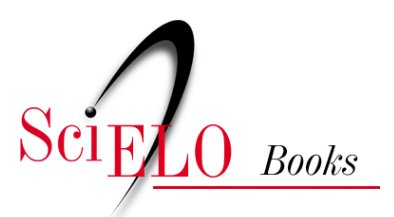

\title{
Música e drama cúmplices sob a mesma luz
}

\author{
Eduardo Tudella
}

\section{SciELO Books / SciELO Livros / SciELO Libros}

TUDELLA, E. Música e drama: cúmplices sob a mesma luz. In: A luz na gênese do espetáculo [online]. Salvador: EDUFBA, 2017, pp. 133-153. ISBN: 978-85-232-1858-4.

https://doi.org/10.7476/9788523218584.0006.

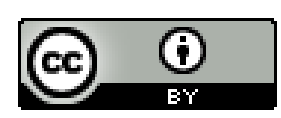

All the contents of this work, except where otherwise noted, is licensed under a Creative Commons Attribution 4.0 International license.

Todo o conteúdo deste trabalho, exceto quando houver ressalva, é publicado sob a licença Creative Commons Atribição 4.0.

Todo el contenido de esta obra, excepto donde se indique lo contrario, está bajo licencia de la licencia Creative Commons Reconocimento 4.0. 


\section{MÚSICA E DRAMA cúmplices sob a mesma luz}

Muitos séculos depois do seu apogeu na Antiguidade, a tragédia grega repercutiria significativamente entre os artistas do século XVI. Certas manifestações do período apontam para um movimento mais agudo da atividade teatral sistematizada, que eclodiria no início do Renascimento, como aquelas que eram efetivadas em instalações provisórias patrocinadas pela Academia Olímpica, fundada em 1556, seguindo a tradição da Academia Platônica, reinventada pelo pensamento humanista do século XVI, na Itália. ${ }^{1}$ Como ressonância da tragédia grega, surgiria na Itália uma manifestação cênica assim definida pelo Oxford Companion to the Theatre: "Uma composição dramática

\footnotetext{
1 As academias renascentistas seguiam uma tradição que se iniciou na Grécia, provavelmente a partir da atividade de Platão, quando ele reunia discípulos, seguidores, para a apresentação dos seus princípios filosóficos, nos arredores de Atenas, no jardim público, denominado Academia, cujo nome pode ter sido originado de Hecademus ou Academus, que teria doado o jardim aos cidadãos para a prática da ginástica.
} 
concebida para ser representada no palco, na qual a música vocal e instrumental desempenha função especial".' (HARTNOLL, 1957, p. 585, tradução nossa)

Considerando outra opinião, encontramos uma definição semelhante, em Burton D. Fischer ${ }^{3}$ (2005, p. 14, tradução nossa): "A ópera4 é um modo formal do teatro que expressa sua essência dramática integrando palavras e ações com música. Como drama, a ópera incorpora todo o espectro dos elementos teatrais: diálogo, interpretação, figurinos, cenário e ação, [...]". ${ }^{5}$ Artistas italianos do período em questão acreditavam estar refazendo a tragédia, como uma manifestação cênica em grande parte cantada e parcialmente dançada; produzindo a interação de música e dramaturgia, eles incorporaram condições técnicas da época - tochas, velas, lamparinas a óleo e tratamento cenográfico, com repercussões renascentistas. O estudo da ópera, por conseguinte, há de contribuir para a observação das relações entre a luz e a práxis cênica.

Para compreender o contexto no qual a ópera se insere, vale a pena mencionar as relações de poder estabelecidas pela presença da Igreja Católica na Itália. Acentue-se que, assim como o teatro permaneceu durante muito tempo uma atividade proscrita - desde o século V d.C. -, só reaparecendo como forma expressiva oficialmente reconhecida, a partir da sua reelaboração no interior dos templos católicos, também a música secular alcançou o status de expressão artística condenada pela Igreja. Por outro lado, no ambiente religioso, o canto gregoriano de princípio monofônico - em uma única linha melódica - com ou sem acompanhamento instrumental, era largamente usado. A música executada fora da Igreja Católica era execrada e, simultaneamente, a vida monástica estava repleta de salmos e hinos que constituíam parte importante das orações durante a missa. Mais uma vez caía por terra a intenção de sufocar uma expressão artística. A diversidade de vozes que se instalou progressivamente nas composições, já fortalecia os caminhos do interesse pela polifonia, ${ }^{6}$ ainda que a pluralidade de vozes não

\footnotetext{
2 "A dramatic composition, intended to be represented on the stage, in which vocal and instrumental music plays an essential part."

3 Maestro que estudou na Julliard School, em Nova York, autor de mais de uma centena de livros sobre a ópera.

4 Opera, plural de opus, em latim, significa obras.

5 "Opera is a formal theatrical medium that express its dramatic essence by integrating its words and action with music. Like drama, opera embraces the entire spectrum of theatrical elements: dialogue, acting costumes, scenery, and action, [...]."

6 Do termo grego polyphōnos: poly, muitos e phōnē, voz. Uma textura musical caracterizada pela presença de diversas vozes melódicas, ao contrário da monofonia - música com apenas uma voz - ou homofonia - música com uma voz dominante acompanhada por cordas. O termo é usado para referir-se inicialmente a mudanças que começam a aparecer na música do final da Idade Média.
} 
incluísse, inicialmente, uma intenção de contraponto ${ }^{7}$ e preservasse a importância, o valor de cada linha melódica.

Os encaminhamentos de tais conflitos contribuíram, entre outras coisas, para o aparecimento de duas formas musicais que são apontadas como precursoras da ópera moderna. O madrigal e a pastoral combinavam dramas poéticos e acompanhamento instrumental, com uma diferença importante no contexto: o primeiro lidava com temas da liturgia, com temas bíblicos, era ligado às atividades sacras, aos rituais, às moralidades e aos milagres; a segunda incorporava motivos seculares à simplicidade da vida rural, sua contraposição ao luxo e à corrupção das cidades e da corte, envolvendo, nos contrastes, a alegria, a traição, a presença de entidades mágicas, assim como a de heróis. Estudiosos acreditam que nelas pulsavam os germens da expressão artística que integraria poesia dramática e música, construindo progressivamente a ópera.

Deve-se enfatizar que a Igreja proibiria os madrigais, precisamente porque 0 grau de contraponto do qual eles foram impregnados representavam impasses à apreensão do texto da missa, interferindo na liturgia, dilapidando a função de catequese, de afirmação da fé, e subvertendo a estrutura dos serviços religiosos.

O madrigal tornou-se a forma vocal dominante e era praticado com maestria pelos compositores italianos. A Reforma Protestante originou a Contrarreforma Católica, que culminou no Concílio de Trento $^{8}$ e impôs estritas limitações à polifonia vocal, que favorecia o estilo de Palestrina, ${ }^{9}$ o qual permitia que o texto fosse claramente apreendido [...]. ${ }^{10}$ (GREENBERG, 1998b, p. 23, tradução nossa)

7 Contraponto, ou a habilidade particular da música, de acordo com o The Concise Oxford Dictionary of Music, de dizer duas coisas ao mesmo tempo, de modo compreensível. Interessados no estudo do contraponto podem pesquisar as possibilidades musicais da adição de uma "parte" ou uma "voz" a outra, ou a combinação simultânea de vozes; cada uma delas com sua significação e característica em si mesma. Em música, isso pode resultar numa textura íntegra, com uma especial ordem interna. Para aprofundar esse caso, é recomendável o estudo da polifonia.

8 Entre 13 de dezembro de 1545 e 4 de dezembro de 1563 ocorreu em Trento, na Itália, o décimo nono conselho ecumênico da Igreja Católica, numa resposta à Reforma Protestante, o que incluiria uma revisão do comportamento no interior da Igreja, eliminando o que ela considerava inadequado. Devem ser destacados os 18 anos de duração do Concílio de Trento, necessários para as demoradas discussões das questões teológicas, políticas, das regras do teatro neoclássico, de questões jurídicas - direito canônico e direito geral. Tratava-se de uma reformulação dos aspectos éticos, artísticos, morais e teológicos, que interferiram politicamente no mundo ocidental. Foi o mais longo concílio da história da Igreja Católica.

9 Considerado o maior entre os compositores da música litúrgica, Giovanni Pierluigi ficou conhecido pelo nome da sua cidade natal, Palestrina. Nasceu entre 1514 e 1526 e morreu em 1594, na cidade de Roma.

10 "The madrigal became the dominant Renaissance vocal form, and it was mastered by the Italian composers. In reaction to the Protestant reformation, the Catholic Counter-Reformation culminated in the Council of Trent, which 
A $22^{\text {a }}$ seção do Concílio de Trento, realizada em 17 de setembro de 1562, presidida pelo papa Pio IV, lista o que deveria ser atendido e aquilo que deveria ser evitado na missa: "[...] banir das igrejas todo o tipo de música na qual, executada através do órgão ou cantada, se mistura qualquer lascívia ou impureza".11 (THE COUNCIL..., 1848, p. 161, tradução nossa) Se não lasciva, ao menos impura seria toda música que impedisse o fiel de assimilar a palavra da Igreja.

Ainda sob o impacto do Concílio trentino, na transição entre os séculos XVI e XVII, as primeiras iniciativas de "invenção" da ópera eram tomadas em Florença, no centro da Itália. Já em janeiro de 1593, na casa do conde Giovanni Bardi, um grupo de poetas e músicos reunia-se em torno de um pensamento norteador, que criticava a música de seu tempo, tomando o nome de Camerata ${ }^{12}$ de Bardi, também conhecida como Camerata florentina. Voltando-se para traduções de textos antigos, eles acreditavam - como muitos pensadores da época - que o caminho para a reedificação da arte musical estava no retorno às raízes gregas. A influência de Girolamo Mei (1519-1594), estudioso da cultura grega antiga, ganhou força na discussão do teatro grego. Em longas discussões, o círculo de músicos e literatos, que incluía advogados, médicos, farmacêuticos e outros profissionais, tentava reconstruir sua práxis.

A Camerata defendia a aproximação da música de sua época de tais raízes clássicas - um refazer da tragédia grega - como um caminho para a excelência. É importante destacar que os estudiosos tentavam traduzir as versões latinas, como as de Sêneca, no intuito de compreender como as tragédias eram montadas. Com sólidos conhecimentos dos originais da tragédia grega e perfeita leitura do grego clássico, Sêneca adaptou com perícia em suas numerosas versões para o latim de sua época, a arte da métrica dos originais, especialmente os dramas de Eurípedes.

O círculo da Camerata de Bardi, provavelmente impressionado pela força teatral da obra de Sêneca, imaginou que as tragédias da Grécia Clássica eram cantadas, devido à organização musical dos versos, nas adaptações e versões elaboradas por Sêneca. Não há informações claras sobre as técnicas dos atores gregos, restando imprecisões sobre seu canto e sua dança. Os amigos do Conde Bardi, entretanto, pareciam convencidos: os textos da tragédia clássica eram cantados e,

\footnotetext{
put strict limitations on vocal polyphony, and it favored the smooth style of Palestrina, which allowed the text to be heard clearly."

11 "[...] banish from churches all those kinds of music, in which, whether by the organ, or in the singing, there is mixed up anything lascivious or impure."

12 Literalmente, aqueles que se reúnem numa câmara.
} 
assim, reformularam a Tragédia Grega Clássica como uma representação cantada, apontando para a Ópera.

As pesquisas levaram ao primeiro exercício efetivo no palco, tomando como tema o mito de Apolo e Daphne, apresentado em 1597. O libretto ${ }^{13}$ de Daphne foi assinado por Ottavio Rinuccini (1562-1621), e a música composta por Jacopo Peri (1561-1633). Caracterizada por Peri como "dramma per musica", a obra, infelizmente, se perdeu. A empreitada seguinte, escrita pelos mesmos autores [Eurídice, (1600)], também sob a influência da mitologia grega, adaptada da obra de Ovídio (Publius Ovidius Naso 43 a.c. -17/18 d.C.) [Metamorfosi]. Isso pode indicar uma diversidade de fontes, de provocações para quem se interessa pela ópera, podendo incluir um regente, um diretor e também um iluminador, dentre outros artistas.

A rota proposta pela Camerata Florentina de Bardi indica peças que procuravam instalar um tratamento capaz de reagir à polifonia renascentista, buscando a apresentação integral de um drama, numa estrutura relacionada pelos eruditos à qualidade monódica, ${ }^{14}$ e investindo no diálogo entre uma voz solo que usava linha melódica ornamentada por acompanhamento instrumental. Sem o aprofundamento na análise musical que exigiria maior domínio da questão, observe-se a convicção dos artistas daquele período acerca do poder daquele tipo de obra "cênico-musical", para suscitar profundas emoções e acentuado efeito moral. Ora, combinando tais aspectos e destacando o tema usado por Rinuccini na construção do seu libreto, é possível vislumbrar as possibilidades cênicas do espetáculo que pode ser elaborado a partir das fontes mencionadas, compreendidas como partes vivas da práxis cênica e representando elemento importante para a abordagem aqui encaminhada, quando se as confronta com o desejo expresso pelos artistas que propunham a ópera.

\section{L'ORFEO COMO AFIRMAÇÃO DA LUZ NO DRAMMA PER MUSICA}

Na transição entre os séculos XVI e XVII, os artistas romperam os limites da estética musical do mundo aristocrático, traçando novos caminhos e caracterizando a vida através de uma mentalidade emergente da poderosa burguesia que ascendia na Europa, num processo que envolvia o crescimento das cidades e o desenvolvi-

13 Libretto, diminutivo de libro, em italiano. O libretto traz todo o texto de uma ópera, as rubricas e eventualmente observações da montagem. Em muitos casos, os libretti ficam disponíveis (ou são vendidos) no foyer, o que permite que o público acompanhe o texto cantado. A tradição, que exige dos cantores alta expressividade musical, pode, por outro lado, comprometer a articulação e com isso a compreensão do texto cantado.

14 No sentido musical de melodia - canto - em uníssono. 
mento econômico das Cidades-Estado. Tal atividade se relacionava a um comércio cada vez mais globalizado e o fomento da produção de bens manufaturados.

A burguesia ascendente e enriquecida investiu não apenas no poder políticomilitar, mas também numa educação abrangente e sofisticada para seus filhos, até superando a aristocracia. Pode-se dizer que os aficionados pela música eram amadores no sentido positivo da palavra, na sua maioria, tratando-se de profissionais liberais, advogados, juízes, médicos, entre outros, que tinham no aprendizado musical uma atividade regular de sua formação, estudando disciplinas como harmonia e contraponto, dentre outras, prática já comum na aristocracia e que se estabeleceu na burguesia emergente nas Cidades-Estado da Itália.

Claudio Giovanni Antonio Monteverdi (1567-1643), em particular a sua ópera L'Orfeo, [em parceria com o libreto de Alessandro Striggio (ca. 1573-1630), ${ }^{15}$ publicada na cidade de Mântua em 1607], pode ser mencionada como representante do primeiro estágio de organização da ópera. A escolha de Orfeu como figura central da ópera de Monteverdi/Striggio foi uma decisão emblemática. Na mitologia grega e também na sua acepção romana, ele tinha especial talento musical, com poderes mágicos, era instrumentista virtuose com a lira, inventor da cítara e cantor. Além disso, Orfeu era um semideus, uma personagem próxima do homem que lutava para se impor na ascensão burguesa, e não uma figura mítica isolada na instância divina.

Há versões que o apresentam como filho de Calíope e Oeagrus, um rei da Trácia; no Symposium, Platão afirma que ele é filho de Apollo. Ora, mesmo aceitando a última versão, não se pode esquecer que, ainda assim, Orfeu é o filho da mais importante entre as nove irmãs Musas - filhas de Zeus e pertencentes ao cortejo de Apolo, deus da música; vale lembrar que as Musas se transfiguraram em deusas da inspiração poética. O Dicionário eletrônico Houaiss da língua portuguesa (indica a raiz etimológica do termo música: "[...] mousikós, ê, ón (dórico mousiká) 'que diz respeito às Musas, à poesia, às artes, esp. à música". ${ }^{16}$ Ruth Guimarães (1995, p. 239) acentua, referindo-se a Orfeu: "Suas cantigas eram tão suaves que as feras o seguiam, inclinavam-se as árvores para ouvi-lo e os homens mais coléricos sentiam-se penetrados de doçura e bondade". E acrescenta que ele fez parte da jornada dos Argonautas, ${ }^{17}$ sendo o responsável por estabelecer a cadência dos remadores.

\footnotetext{
15 Filho do compositor de mesmo nome.

16 O Concise Oxford English Dictionary explica: [...] mousiké (tekhné) "(arte) das Musas", de mousa, "muse".

17 O termo deriva de Argo, nome da embarcação de 50 remos, construída por Argus, sob o comando de Jasão, para viajar à Cólquida, em busca do Velocino de Ouro. Acompanhado de uma tripulação composta de mais de quatro dezenas de jovens heróis, depois de uma saga que envolve traição, ganância, bravura e magia, Jasão retorna com o Velocino, entregando-o a Pelias. (GRAVES, 1957)
} 
Na ópera, a saga de Orfeu inicia-se quando sua esposa Eurídice é picada por uma serpente, enquanto foge da perseguição de Aristeu, que em alguns relatos aparece com um sátiro. Diante do corpo sem vida da amada, o herói entoa canções de profundo lamento, fazendo chorar as Ninfas. O imenso amor a ela devotado e o sofrimento originado na perda impelem Orfeu numa jornada ao Hades (do termo grego Haidés, um nome de Plutone, o deus dos mortos), com o intuito de trazê-la de volta à vida.

Uma pesquisa originada pela intenção de aproximar L'Orfeo de Monteverdi e Striggio da práxis cênica, leva a Ovídio e suas Metamorfosi. Mesmo tendo sido acusado de imoral no seu tempo e exilado por ordens do imperador Augusto, a importância de Ovídio para a poesia do Renascimento foi decisiva e L'Orfeo é considerada um relevante modelo para o período. Tratando-se de um clássico, em língua estrangeira, o considerável volume de estudos que incorporam a obra de Ovídio pode sugerir pesquisa exaustiva, mas gratificante, para alcançar abrangência. Destaque-se a abordagem de Italo Calvino (2009, p. 37, grifo nosso), que assim se refere às Metamorfosi:

As metamorfoses são o poema da rapidez, tudo deve seguir-se em ritmo acelerado, impor-se à imaginação, cada imagem deve sobrepor-se a outra imagem, adquirir evidência, dissolver-se. É o princípio do cinematógrafo: cada verso como fotograma deve ser pleno de estímulos visuais em movimento.

Considere-se o interesse de Calvino pela imagem, assimilando a contribuição da imagem para o seu pensamento. A simbiose que faz interagir poesia, imagem e movimento, apresenta um terreno muito fecundo para as reflexões do presente contexto.

O poema de Ovídio é constituído por episódios cuja narrativa elabora uma tessitura de imagens que tomam como provocação a origem do universo, sugerindo investigações acerca de rotas transversais ligadas às ideias provocadoras de um espetáculo:

Antes do mar, da terra e céu que tudo cobre, | Não tinha mais que um rosto a Natureza: | Este era o Caos, massa indigesta, rude, | E, consistente só num peso inerte. | Das coisas não bem juntas as discordes, | Priscas sementes em montão jaziam | O Sol não dava claridade ao mundo, | Nem crescendo outra vez se reparavam | As pontas de marfim da nova Lua [...]. (OVÍDIO, 2006, p. 1, grifo nosso) 
Num constante fluxo que desliza vigorosamente constitui-se a desordem imposta no conflito instaurado pela ausência da luz. Na tradução do poeta português Manuel Maria de Barbosa l'Hedois du Bocage (1765-1805), o sol aparece em lugar do Titã, e Febe ${ }^{18}$ assume a figura da lua crescente, com suas extremidades pontiagudas; trata-se de uma configuração de natureza poética, já que o autor introduz a lua sem que ela existisse, pois suas fases dependem da relação direta com o sol, que ainda não iluminava o mundo.
Ar, e pélago e terra estavam mistos:
As águas eram, pois inavegáveis.
Os ares negros, movediça a Terra,
Forma nenhuma em nenhum corpo havia,
E neles uma coisa a outra obstava,
Quem em cada qual dos embriões enormes
Pugnavam frio, e quente, úmido, e seco,
Mole, e duro, o que é leve e o que é pesado.
(OVÍDIO, 2006, p. 15-16)

Na condição de verbos ativos, obstar e pugnar indicam a tensão presente na "[in] existência" composta de ares negros, que precedem a introdução da luz, e indica a energia que instalará a vida no planeta. No Livro I, Ovídio (2006, p. 16) trata da transformação do caos em organismo de nova ordem: "[...] Para que a Terra | não fosse desigual em parte alguma, | Por todas a compôs na forma de orbe". ${ }^{19}$ Ele insere a fábula de Orfeu no Libro (ou capítulo) X da Metamorfosi, que se apresenta como um poema sequenciado num total de 15 libri. Assim como na abertura do mito da criação, o poema se inicia nas trevas:

De rutilantes vestes adornado

Himeneu rompe o ar, à Trácia voa

Lá donde o chama Orfeu, porém debalde.

O deus sim presidiu do vate às núpcias

Mas não levara ali solenes vozes,

Nem presságio feliz, nem ledo rosto.

Sentiu-se apenas crepitar-lhe o facho,

E em vez de viva luz soltar um fumo

\footnotetext{
18 Ou Phoebe, o termo pode ser compreendido como "brilhante", referindo-se a primeira deusa da Lua na mitologia grega.

19 Orbe, em latim orbis, ou qualquer figura esférica ou circular.
} 
Tentou co [sic] movimento erguer-lhe a chama.

$\mathrm{O}$ efeito foi pior que o mesmo agouro.

(OVÍDIO, 2006, p. 77, grifo nosso)

Convidado por Orfeu para a celebração de sua união com Eurídice, o deus Himeneu $^{20}$ vê sua tocha fracassar e não prover a luz que o júbilo da ocasião demanda, mergulhando em fumaça o ambiente. Uma poderosa imagem anunciadora dos eventos e, portanto, da atmosfera que se aproxima. Na versão usada por Striggio, a heroína morre depois de picada por uma serpente, enquanto passeava acompanhada das ninfas. Após chorar a dor da sua enorme perda, o semideus decide confrontar as sombras das profundezas e trilha os rumos negros do rei das trevas. ${ }^{21}$ (OVÍDIO, 2006) Entoando versos e tocando a lira, faz da música sua força e do seu amor o suporte da resignação, para até mesmo permanecer no Hades, se ali estiver a solução para continuar perto de sua mulher: melhor prisioneiro das trevas do que retornar sem a amada.

O poder da música comove Proserpine (nome de Perséfone, entre os romanos), que intercede a seu favor e convence o marido Plutone (Hades); Orfeu tem de volta a esposa, ganhando o direito de levá-la num triunfal retorno à vida, sob uma condição: “[...] Recebe o trácio Orfeu sua bela esposa | Lei de que para trás não volte os olhos | Enquanto for trilhando o feio abismo, | Se nula quiser a graça extrema”. (OVÍDIO, 2006, p. 79) Ora, é uma grave imposição: ter bem próxima de si a mulher amada, suplantando tamanho infortúnio e alcançando imensurável vitória, sem poder vê-la. Orfeu dirige-se para longe das trevas, seguido de Eurídice; a tentação e o desejo de contemplá-la, de confirmar sua presença com a visão, entretanto, levam-no a - já nas fronteiras entre o tártaro e a luz - olhar para trás:

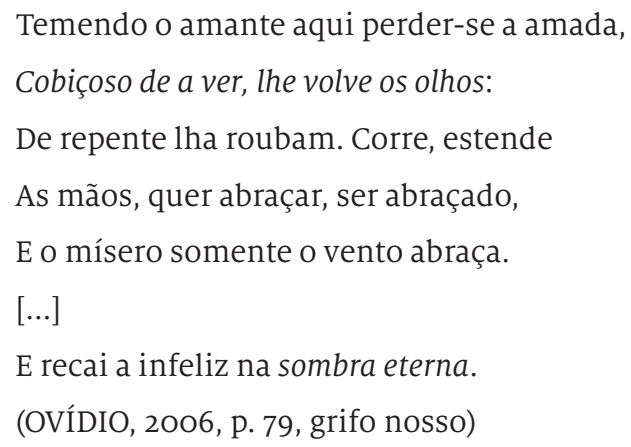

\footnotetext{
20 Hymeneos, na sua forma grega, era o deus do casamento. Também conhecido como Hymenaeus ou Hymenaios em latim; filho de Apolo e Afrodite.

21 Nota da tradução de Bocage esclarece: “Orco, que corresponde ao grego Hades”. (OVíDIO, 2006, p. 78)
} 
Orfeu sucumbe à tentação da visão, da luz, e paga por isso, pois, mesmo alcançando a vida, mergulha nas trevas da sua perda. Desrespeitando o acordo, ele vê o objeto da sua paixão pela última vez: Eurídice desvanece, transformando-se numa sombra e sumindo para sempre. Retornando sozinho à superfície, ele mantém inabalável a fidelidade e o amor por Eurídice, alimentando o ciúme e a ira das bacantes, que o matam. Como em grande parte dos temas da mitologia, há versões e interpretações diferenciadas e ambíguas.

\section{L'ORFEO DE MONTEVERDI E STRIGGIO}

Monteverdi e Striggio aceitaram a provocação do mito de Orfeu e Eurídice para criar L'Orfeo. Familiarizado com as imagens fantásticas que permeiam a poesia de Ovídio, o leitor pode elaborar seu próprio ponto de vista sobre a mesma, incorporando os benefícios de tal familiaridade. Aproximar-se da ópera pode contribuir para as trocas que o contato com uma obra de arte promove. Ainda que tal estágio possa incluir flexibilidade para se misturar ao universo particularmente criado pelos autores do libreto e da música, o trânsito pelas Metamorfosi pode contribuir para uma compreensão diferenciada. Tal compreensão pode atuar como alicerce, chama, tempero, como hedusma na construção das imagens na cena. O mito agora funde-se à música e vice-versa: linha melódica, narrativa, diálogo verbal, acento, andamento, registro, volume, som e palavra, todos estes elementos coabitam o mesmo ambiente.

O texto de Striggio, assim como a música de Monteverdi, na condição de respostas estéticas às provocações ovidianas, constituem outro possível caminho. A investigação das relações entre texto e música pode estimular a imaginação de qualquer artista envolvido na construção da cena. Se ele for o iluminador, as imagens passarão por um toque seu, particular, único. A aproximação com a visualidade, já presente na narrativa de Ovídio, pode ser de grande ajuda em seu trabalho.

Parece óbvio que a variedade de fontes disponíveis, além da obra de Monteverdi, propriamente dita, abre diversas vias de interpretação musical da dramaturgia.

O Orfeo de Monteverdi tornou-se uma síntese de formas musicais do Renascimento, tendo o compositor adaptado e estendido madrigais e pastorais para responder às necessidades do seu drama musical, dotando-o de intensa expressividade. [...] | Monteverdi tornou-se também um pioneiro da instrumentação dramática: ele ampliou os recursos da orquestra, percebeu o seu 
incomparável espectro, poder e timbres variados, e reconheceu o seu poder de reforçar a representação dramática. Ele afirmava que teria inventado o tremolo nas cordas e o pizzicato. | o Orfeo de Monteverdi foi a primeira ópera de sucesso; ela representava uma síntese dos elementos teatrais conhecidos como cenografia, dança e balé, canções e baladas, coros nos estilos do madrigal e da pastoral, e recitativos; todos estes elementos foram integrados em uma ópera, uma integração singular de todos os elementos teatrais. ${ }^{22}$ (FISCHER, 2005, p. 20, tradução nossa)

Uma discussão da natureza compósita da arte teatral, sua manifestação como Gesamtkunstwerk, termo alemão para obra de arte integrada ou obra de arte total, deve se iniciar com o estudo do L'Orfeu, música de Monteverdi e libreto de Striggio. Antes do prólogo, o compositor insere uma tocatta, atendendo provavelmente a convenções do período, que demandavam, na corte de Mântua, uma saudação ao duque, fazendo impregnar os metais - trompetes - de uma qualidade marcial, encaminhando para a introdução do prólogo, numa atmosfera mais suave, rotunda. Uma análise mais aprofundada de questões específicas de natureza musical, assim como o estudo das diversas fontes que discutem uma obra de tamanha complexidade, abriria uma digressão no presente trabalho, além de exigir alto grau de familiaridade com questões específicas do campo musical.

Por outro lado, considerando que, dentre as diversas provocações às quais Monteverdi responde para escrever a peça, está incluído o libreto de Striggio, interessa a importância que a dramaturgia ganha, logo no início da história da ópera, em que a apreensão da fábula é condição imprescindível. Assim como a emoção inscrita na peça de Monteverdi, o trabalho de Striggio pode ser sublinhado para dialogar com a crença de que ele, assumindo o papel de dramaturgo, já incorpora a luz, ao elaborar sua obra. O compositor recebeu, então, contundentes provocações originadas pelo texto e respondeu com sua música.

Trata-se de uma ópera, cuja primeira personagem a intervir é a própria Música. Como uma entidade investida de poderes especiais, ela abre possibilidades para a imaginação, provocando os artistas envolvidos na construção da cena:

\footnotetext{
22 "Monteverdi's Orfeo became a synthesis of extant Renaissance musical forms, the composer adapting and expanding madrigals and pastorals to suit the needs of his music drama, and endowing them with an intense expressiveness. [...] | Monteverdi also became a pioneer in dramatic instrumentation: he extended the resources of the orchestra, realized its unrivalled range, power, and varied tone colors, and recognized its power to enhance the dramatic representation; he claimed that the string tremolo and the pizzicato were his own discoveries. | Monteverdi's Orfeo was the first successful opera; it represented a synthesis of existing theatrical elements, such as stage scenic design, dance and ballet episodes, songs and ballads, madrigal-style and pastoral-style choruses, and recitative; all of these parts were integrated into an opera, a singular integration of all theatrical elements."
} 
Eu sou a Música, que com doces acentos

sei tranquilizar os corações exaltados,

e com nobre ira ou com amor

posso inflamar as mentes mais frias

[...]

Com a minha cítara de ouro eu sei

lisonjear e encantar o ouvido dos mortais

e da mesma forma, com a harmonia sonora

da lira do céu, ainda mais envolvo as almas. ${ }^{23}$

(STRIGGIO, 2011, p. 23)

Merece especial atenção a ousadia de Monteverdi, ao escrever uma composição que deseja expressar os poderes profundos e mágicos da própria música. Cabe sublinhar o tema escrito para a Música, repetido em momentos chaves de L'Orfeo, desde aquele que antecede sua entrada propriamente dita, sugerindo aquilo que se conhece hoje como o leitmotiv, que repercutiria em toda a história da ópera, e, de modo decisivo, na obra de Richard Wagner (1813-1883), séculos depois. Burton D. Fischer (2005, p. 20, grifo nosso), cuja obra já foi mencionada, acentua: "L'Orfeo de Monteverdi utiliza muitas tradições que ainda hoje aparecem na ópera: recitativo, arioso, dueto, interlúdios corais e de dança, caracterização musical e continuidade através do leitmotiv". ${ }^{24}$

Donald Jay Grout e Hermine Weigel Williams, autores de A Short History of Opera, comentam e exemplificam:

[...] O prólogo que precede a entrada de Orfeo abre com um ritornello ${ }^{25}$ que é repetido quatro vezes numa versão reduzida depois de cada stanza ${ }^{26}$ e executada integralmente uma vez no final do prólogo. Além disso, Monteverdi traz o mesmo ritornello no fim do Ato IV, conclusão de significante ação dramática - construindo assim um tipo de leitmotiv, sim-

\footnotetext{
23 “Io la Musica son, ch'ai dolci accenti | so far tranquillo ogni turbato core, | et or di nobil ira et or d'amore | poss'infiammar le più gelate menti. [...] lo su cetera d'or cantando soglio | mortal orecchio lusingar talora; | e in questa guisa all'armonia sonora | de la lira del ciel più l'alme invoglio."

24 "Monteverdi's Orfeo utilizes many traditions that still dominate opera today: recitative, arioso, duet, choral and dance interludes, musical characterization, and continuity through leitmotiv."

25 Uma espécie de refrão musical que se repete em uma obra musical de natureza vocal.

26 Versos ou linhas em um poema; um conjunto de linhas que constroem uma unidade métrica básica e recorrente em um poema. Um grupo de quatro linhas em certos exemplos da métrica antiga, na poesia grega e também latina.
} 
bolizando o 'poder da música', a ideia central da ópera [...]. ${ }^{27}$ (GROUT; WILLIAMS, 2003, p. 53, grifo e tradução nossos)

Tal menção ao leitmotiv importa aqui como estratégia para a observação da atmosfera pretendida por Monteverdi. Não somente no que se refere às características musicais do ritornello em si, mas também na decisão do compositor, repetindo-o, nos finais dos atos II e IV, e elaborando uma pulsação de qualidade particular (Figura 13).

No prólogo escrito por Striggio, a Música deixa um alerta do seu poder, cujo eco se manifestará na obra como um todo:

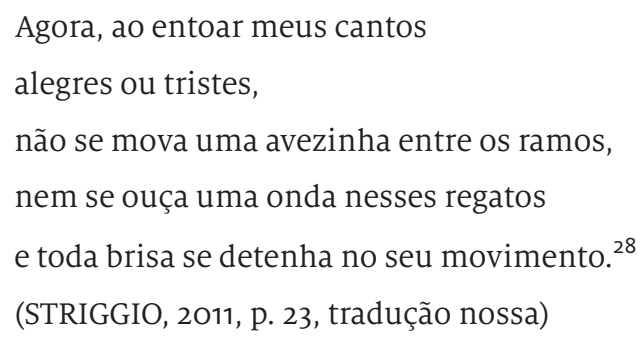

No início da ópera, pulsa uma luz cuja qualidade é principalmente subjetiva, que se entrelaça e propõe trocas com as instâncias metafóricas de um arquétipo de tamanha dimensão. Cabe acentuar a ousadia de ambos, ao escreverem texto e música para personagem de tamanha relevância na história da cultura, lembrando que a relação de Orfeu com a música começa quando o próprio Apolo o presenteia com uma lira e, em seguida, as Musas o ensinam a tocar. (GRAVES, 1957)

O texto dramático é construído por Striggio em cinco atos, com diferentes ambientes para a ação - primeiro, segundo e quinto, em lugares na Trácia; terceiro e quarto, nos caminhos e nas profundezas do Hades - oferecendo ao iluminador a possibilidade de elaborar diversificação visual, desde o prólogo, já na transição para o primeiro ato. Todo o libretto, afinal, encontra-se impregnado de visualidade específica, despertando a atenção daquele que se interessa por tal abordagem. Já na abertura do Ato 1, um pastor revela: "Neste dia alegre e afortunado [...]". ${ }^{29}$ (STRIGGIO, 2011, p. 24, tradução nossa) Ficam indicados tempo e atmosfera, o que

\footnotetext{
27 " $[. .$.$] the prologue to Orfeo opens with a ritornello what is repeated four times in a shortened form after each$ stanza and once in its original form at the end of the prologue. Moreover, Monteverdi brings in the same ritornello at the end of Act IV, the close of the significant dramatic action - thus making it a kind of leitmotiv symbolizing the 'power of music', the central idea of the opera [...]."

28 "Or mentre i canti alterno, | or lieti or mesti, | non si mova augellin fra queste piante, | Ne s'oda in queste rive onda sonante, | Et ogni auretta in suo cammin s'arresti."

29 "In questo lieto e fortunato giorno [...]."
} 
introduz nova qualidade, trazendo certos índices do ambiente corporificado: é dia, e se trata de um dia específico, um dia de bem-aventurança, num sítio rodeado de bosques, como se pode ler: "[...] Hoje Orfeu tornou-se feliz | nos braços da dela, por quem tanto | nestes bosques ele suspirou e soluçou [...]". ${ }^{\circ}$ (STRIGGIO, 2011, p. 24)

Assim como nas diversas indicações do ambiente, a abertura indica o caminho repleto de imagens que povoam a poesia de Striggio (2011, p. 24, grifo e tradução nossos): "Deixai os montes, | deixai as fontes, | ninfas belas e alegres | nestes prados | com as danças costumeiras | oferecei gracioso vosso belo pé [...]". ${ }^{31}$ Imagens que, além de projetarem a elaboração do ambiente, deixam uma pista significativa para as mudanças na atmosfera, como neste último trecho, quando o poeta provoca: exponham vossos belos pés. Parece possível ligar tal momento à morte de Eurídice. Em seguida, o Coro de Ninfas e Pastores pede a intervenção de Himeneu, invocando um contraste do qual a cultura ocidental se encontra impregnada:

Vem, Himeneu, oh, vem, | Que o teu rosto radiante | Seja quase um sol nascente, | E traga a estes amantes os dias serenos, le para longe afaste sempre | os anseios, a dor, os horrores e $a$ sombra. | [...] Que o sol contemple | Vossas rodas, | Bastante mais graciosas | Do que aquelas que em redor da lua | Na noite escura, | As estrelas dançam no céu. ${ }^{32}$ (STRIGGIO, 2011, p. 24-25, grifo e tradução nossos)

A crença no Sol, na luz como afirmação positiva capaz de vencer a sombra, caracterizada como força negativa, ecoa também na obra de Striggio. Revela-se, portanto, substancial parceria com a visualidade, expressa tanto na música quanto no texto dramático, assim como na estreita relação que qualifica cada um dos aspectos mencionados como agentes decisivos na elaboração da ação, do seu ambiente e da atmosfera. Desde o primeiro ato, que pode ser compreendido como uma celebração do amor entre Orfeu e Eurídice - presentes em cena, numa corporificação do amor - até o ato final, quando ele perde sua amada para as profundezas e para sua incerteza. Evitando o excesso de detalhes, no que se refere às inúmeras provocações deixadas, tanto por Striggio quanto por Monteverdi, podem ser citados alguns trechos, além daqueles já mencionados.

\footnotetext{
30 "[...] Oggi fatto é felice | Orfeo nel sen di lei, per cui giá tanto | per queste selve ha sospirato e pianto. [...]."

31 "Lasciate i monti, | Lasciate i fonti, | Ninfe vezzose e liete. | E in questi prati | Ai balli usati | Vago il bel piè rendete."

32 "Vieni, Imeneo, deh, vieni, | e la tua face ardente | sia quasi un sol nascente | ch'apporti a questi amanti i dì sereni | e lunge omai disgombre | degli affanni e del duol gli orrori e l'ombre. [...] qui miri il sole | vostre carole, | più vaghe assai di quelle | ond'alla luna, | la notte bruna, | danzano in ciel le stelle."
} 
Diversas vezes o poeta traz as relações entre o sol, a lua, as estrelas e suas implicações em luz e sombra, elaboradas como presença nas emoções; o trabatho de qualquer interessado nas questões que envolvem visualidade e cena pode exigir atenção na busca da contribuição das mencionadas relações para o espetáculo, não somente na sua condição de práxis, mas também de pensamento visual.

O primeiro ato revela o contraste entre o infortúnio ao qual Orfeu esteve submetido e a felicidade trazida pela presença de Eurídice. Definindo o sol como rosa do céu e vida do mundo, o semideus pergunta: "[...] ó Sol que tudo envolves e tudo contemplas | no teu movimento sideral, | diz-me, terás visto alguma vez | um amante mais feliz e afortunado | do que eu?"33 (STRIGGIO, 2011, p. 25, grifo e tradução nossos) A resposta para tal pergunta tem grande relevância, pois, segundo Orfeu, o sol é aquele que tudo vê, está munido de absoluta onisciência, tem poderes divinos. Momentos antes do fim do primeiro ato, o coro de ninfas e pastores corporifica a atmosfera na qual a ação cênica se encontra mergulhada: "[...] Pois após as nuvens de chumbo | que trazem no ventre | a furiosa tempestade, que o mundo espanta | vem o Sol e lança mais claros | seus raios luminosos. [...]".. ${ }^{34}$ (STRIGGIO apud MONTEVERDI, 2011, p. 26, tradução nossa) Em seguida, um dueto de pastores canta, assentando o ambiente: "E depois do áspero e despido gelo do inverno, | a primavera veste os campos de flores. [...]".35 (STRIGGIO, 2011, p. 26, grifo e tradução nossos)

É notável, portanto, o empenho do libretista em elaborar relações entre ambiente, atmosfera e desejos. O Ato 2 é iniciado num alicerce semelhante, já na sinfonia escrita por Monteverdi, irradiando-se pelo texto e pela música, confirmando a atmosfera de júbilo que emana da felicidade do amante e amado Orfeu. Em toda intervenção, de qualquer que seja a personagem presente na mencionada parte inicial do Ato 2, tais relações são acentuadas de modo consistente. Os bosques, as montanhas, os prados, as árvores, os campos gramados, as águas, as flores, os pomares, as rochas, tudo agora está abençoado e envolto pela bem-aventurança que se origina nos fulgurosos raios de Phoebus. ${ }^{36}$

As emoções que pairam no ambiente são a felicidade, o amor e a fortuna, que sobrepujaram o tormento, a tristeza, a aflição, a pena e o lamento. Mais uma vez,

\footnotetext{
33 "Sol, che'l tutto circondi e'l tutto miri, | dagli stellanti giri, | dimmi, vedestu mai | i me più lieto e fortunato amante?"

34 "Che, poiché nembo rio gravido il seno | d'atra tempesta inorridito ha il mondo, | dispiega il sol più chiaro i rai lucenti."

35 "E dopo l'aspro gel del verno ignudo | veste de fior la primevera e campi."

36 Phoebus Apollo ou Apolo, o brilho reluzente.
} 
Orfeo expressa seu amor por Eurídice e a atmosfera interage com tal sentimento. Um dos pastores sublinha: "Olha, pois, Orfeu, como sorriem | em redor os bosques e os prados! | Prossegue, pois, com tua inspiração dourada | e suaviza o ar neste dia bem-aventurado". ${ }^{37}$ (STRIGGIO, 2011, p. 28, tradução nossa) Em um dia abençoado, poesia e música preenchem o ar de um doce tom, desde o horizonte; repentina e abruptamente irrompe a Mensageira, em um recitativo ${ }^{38}$ no qual Monteverdi apresenta uma contribuição importante, ampliando a função de explicitar o texto, qualificando-o como elemento decisivo para a proposição do dramma per música, incorporando acentuada qualidade expressiva: "Ai, amarga desgraça! Ai, destino ímpio e cruel! | Ai, estrelas injuriosas! | Ai, céu ruim!".39 (STRIGGIO, 2011, p. 28, tradução nossa) Para ela, a existência tornou-se amarga e cruel como resultado da ação de entidades celestes: "A tua amada esposa morreu".40 (STRIGGIO, 2011, p. 29, tradução nossa)

Daí em diante, por todo o ato, a primeira intervenção da Mensageira é repetida por um pastor e pelo coro, que com ela encerram esse momento da ação no qual se toma conhecimento que Orfeo descerá às profundezas, com o intuito de trazer sua amada de volta à vida. Temos, então, uma espécie de divisão do ato, em duas partes, que podem ser compreendidas - cada uma delas - como um crescendo particular, em diferentes direções: a felicidade da primeira metade e o luto da segunda. Na verdade, a primeira atmosfera funciona como uma preparação para o contraste que se estabelecerá na elaboração da segunda parte, numa estratégia definida pela poesia e pela música:

De acordo com a cor sonora dos instrumentos, o universo de Orfeo é dividido em duas partes: uma luminosa e transparente, tendo como base os violinos e as flautas, que evoca o mundo pastoril e da felicidade, e a outra, sinistra e ameaçadora, com instrumentos de sopro graves, sobretudo os metais, invocando o mundo dos mortos. (FRAGA; MATAMORO, 2011, p. 15)

Assumindo tal estratégia, o autor do libreto anuncia, já nas primeiras palavras de Orfeu no ato seguinte, em diálogo com a Speranza: "Escoltado por ti, ó deusa

\footnotetext{
37 "Mira, deh mira, Orfeo, che d'ogni intorno | Ride il bosco e ride il prato. | Segui pur col plettro aurato | D’addolcir l'aria in sì beato giorno."

38 "Parte declamada da ópera, responsável por narrar o desenvolvimento da ação, em complemento às árias, dedicadas à reflexão que contém geralmente uma somatória de sentimentos. Normalmente escrito para uma única voz, o recitativo desenvolve-se para atender mais aos ritmos e acentos do texto do que à riqueza melódica. Se a ária pode ser apreendida como lugar dos sentimentos, no recitativo, a razão e a disputa aparecem."

39 "Ahi caso acerbo, ahi fat'empio e crudele. | Ahi stelle ingiuriose, ahi ciel avaro."

40 "La tua dilleta sposa è morta."
} 
| Esperança, único consolo | dos mortais aflitos, | chegamos à fronteira | destes reinos tristes e tenebrosos, onde jamais um raio de sol penetra [...]".41 (STRIGGIO, 2011, p. 32, grifo e tradução nossos) O texto impõe-se como uma obra exemplar: invocando o contraste entre o brilho dos dias afortunados que antecedem a morte de Eurídice e as trevas, as sombras nas quais proliferam choro e tristeza, durante a viagem de Orfeu ao vale dos mortos, põe-se em destaque a presença da luz na construção da ação cênica. Pode-se dizer que o tema central da ópera é a oposição entre luz e sombra. Uma comparação entre a fala de Orfeu, mencionada acima, e a que será mencionada a seguir, demonstra os compromissos que Striggio mantinha com a luz. Na abertura do Ato 2, diz o semideus: "Eis-me aqui, que a vós retorno | caros bosques e rios amados, | vós que sois benditos por este sol, | que as minhas noites transforma em dias [...]".42 (STRIGGIO, 2011, p. 27, tradução nossa)

Ainda que o compositor tenha incluído um baixo entre os quatro níveis de vozes, no coro de pastores já no primeiro ato, a aparição de Caronte ${ }^{43}$ - ele sim, um baixo com destaque solístico - no terceiro ato, corporifica a atmosfera anunciada por Orfeu e já presente na transição entre o segundo e o terceiro atos. Impedido pelo obstinado barqueiro de cruzar as águas escuras de lama e lodo do Estige e do Aqueronte, em direção ao vale dos mortos, o herói emprega o poder da música, toca sua lira e canta a ária que é considerada por muitos o ponto alto musical da ópera em questão:

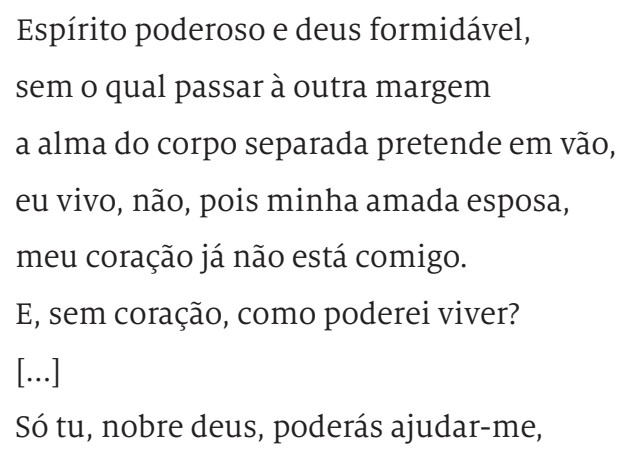

\footnotetext{
41 "Scorto da te, mio Nume | Speranza, unico bene | degli afflitti mortali, omai son giunto | a questi mesti e tenebrosi regni | ove raggio di sol giammai non giunse."

42 "Ecco pur ch'a voi ritorno, | care selve e piaggie amate, | da quel sol fatte beate | per cui sol mie notti han giorno."

43 Em grego, Xóp $\omega v$ - o brilho é um Gênio velho e barqueiro do rio Aqueronte, nas fronteiras do inferno; filho de Érebo e da Noite, tem como função transportar as sombras dos mortos na sua barca escura, atravessando o pantanoso rio e garantindo que os mortos cheguem ao seu destino, o Hades. Caso contrário podem permanecer no rio por muitos anos. Os gregos temiam que eles, então, retornassem à luz. Por isso o barqueiro é recompensado pelos vivos que põem duas moedas na boca - ou uma em cada olho - dos seus mortos, assegurando a travessia. (GUIMARÃES, 1995, p. 98)
} 
E temer não deves, que apenas

De uma cítara de outro

De suaves cordas venho armado,

Contra a qual em vão se insurge a dura alma. ${ }^{44}$

(STRIGGIO, 2011, p. 33, tradução nossa)

Caronte, por sua vez, sucumbe à força do amor e da música:

Muito me agrada, pois,

E me encanta o coração

ó cantor desconsolado,

teu pranto e teu canto $[\ldots] .{ }^{45}$

(STRIGGIO, 2011, p. 34, tradução nossa)

Agora Orfeu tem aberto o seu caminho para a mais profunda região do Hades. E, diante do triunfo da música sobre a vigilância de Caronte, fica cada vez mais configurada a atmosfera de fantasia anunciada desde que o herói decide mergulhar nos abismos para trazer de volta a esposa morta. Alcançando o profundo e escuro vale da morte, ele recebe o apoio de Proserpine, mulher de Plutone, logrando assim a autorização para resgatar Eurídice. Em um momento de tensão e suspense, a fala da dama dos infernos ganha importância especial. Ela diz: "Senhor, esse infeliz | que por estes campos da morte | vem chamando Eurídice [...]". ${ }^{46}$ (STRIGGIO, 2011, p. 34, tradução nossa)

Qualquer que fosse a personagem incumbida de falar agora, ela diria algo muito parecido com a frase escrita para Proserpine, pois estaria cumprindo a função de elaborar o ambiente e a atmosfera da ação. Como se os autores estivessem respondendo a algo maior que eles, já presente na natureza da práxis cênica, as personagens assumem sucessivamente a função de indicar os ambientes e as atmosferas.

Espíritos no coro do Hades usam expressões como "sombra eterna" e "horríveis cavernas"47 (STRIGGIO, 2011), estabelecendo contrastes com a ação, acentuando o amor que une os senhores do Hades. Proserpine diz: “[...] Bendito seja o dia em

\footnotetext{
44 "Possente spirito, e formidabil nume, | senza cui far passaggio a l'altra riva | alma da corpo sciolta invan presume, | (Ritornello) non viv'io, no, | che poi di vita è priva | mia cara sposa, il cor non è più meco, | $E$ senza cor com'esser può ch'io viva? (Ritornello) [...] sol tu, nobile Dio, puoi darmi aita, | né temer dei, | ché sopra un’aurea cetra | Sol di corde soavi armo le dita | Contra cui rigid'alma in van s'impetra."

45 "Ben mi lusinga alquanto | Dilettandomi il core, | Sconsolato cantore, | Il tuo pianto e 'I tuo canto."

46 “Signor, quell'infelice | Che per queste di morte ampie campagne | Va chiamando Euridice, [...].

47 “l'ombre eterne e quest'oribili caverne."
} 
que te agradei, | [...] pois, para minha grande ventura, | pude ganhar a ti, perdendo o sol". ${ }^{48}$ (STRIGGIO, 2011, p. 37, grifo e tradução nossos) Nada pode ser mais grave do que perder o sol, a luz, a visão e o esclarecimento. É como submergir sem forças, afogando-se na alienação em nome do sentimento pelo outro. Somente um amor de dimensão e qualidades incomuns pode justificar tal perda.

Para a mulher apaixonada, dizer ao amado que ele toma o lugar do sol na sua vida é a mais intensa maneira de expressar seu amor. A ação parece descrever curvas que ascendem e descendem, grafadas na música e na dramaturgia. Seguido pela amada no caminho de volta aos prados da Trácia, perseguido pela dúvida, Orfeu tem sua atenção despertada pela música - um som ecoa ao longe - olha para trás e, no mesmo momento, o prazer transforma-se em dor: "Oh, dulcíssimas luzes, posso enfim olhar-vos! | Posso | Mas que eclipse é este, ai de mim, que vos | escurece?". 49 (STRIGGIO, 2011, p. 38, tradução nossa) O prazer de contemplar os olhos de Eurídice converte-se em eclipse, em escuridão, em "não ver" e, portanto, em dor.

O quinto ato revela o retorno de Orfeu à superfície; agora, contudo, a desgraça está definitivamente instalada e ele descreve a natureza abatida pelo seu infortúnio: "[...] Vós gemestes, ó montes, e chorastes | e vós, rochedos, pela partida do nosso sol, | e eu convosco chorarei para sempre [...]".50 (STRIGGIO, 2011, p. 40, tradução nossa)

Nos seus passos iniciais, a ópera deixou-se provocar pela tragédia da Grécia Antiga - cuja música não sobreviveu - e, nos casos de Monteverdi e Striggio, trilhou caminhos indicados pela Camerata de' Bardi. Trata-se de uma obra exemplar, no que se refere à função e à presença da luz. Inúmeras ocorrências de expressões e termos como raio, luz, sol, inferno, treva, sombra, eclipse, estrela, céu, escuridão, propõem estreita relação com a imaginação do espectador, provocando-o a vivenciar relações entre a cena, a vida e a luz.

Considerando que a ópera foi escrita numa espécie de fusão do Renascimento com o Barroco, levando em conta a premissa que indica a ópera Eurídice, de Peri, datada de 1600 , como traço inicial da música barroca, fica enfatizada a permanência da luz na condição de suporte e motriz para a efetivação da práxis cênica, no momento da afirmação do Dramma per Musica. A abordagem renascentista, motivada pela subversão da cosmogonia medieval, indica um deslocamento do ponto

\footnotetext{
48 "Sai benedeto el di che prai ti piacqui | [..] poi Che per mia ventura | fece aquisto di te, perdendo il sole."

49 "O dolcissimi lumi, io pur vi veggio! | lo pur... | Ma qual eclissi, ohimé, | v'oscura?"

50 "[...] Vuoi vi doleste, o monti, e lagrimaste | voi sassi, al dipartir del nostro sole, | ed io com voi lagrimeró mai sempre, [...]."
} 
de vista de observação da luz, reposicionando o ser humano naquela realidade cuja orientação depende do horizonte artificialmente calculado e projetado na perspectiva, da qual trata o capítulo que se segue. O Barroco católico, por sua vez, prima pela unicidade, como conjunto da forte expressividade das emoções, pela afirmação do sentimento religioso. A relevância da luz para a cena, no entanto, mantém-se firme.

Antes de concluir a abordagem de L'Orfeo, é necessário apontar um importante detalhe: ao final do quinto ato, quando resgatado por Apolo - a quem chama de pai - Orfeu pergunta, no texto originalmente atribuído a Striggio (2011, p. 40, grifo e tradução nossos): "E não verei nunca mais | da amada Eurídice os doces raios de luz?." ${ }^{51}$ A simples presença do termo 'raio' impele a tradução a incluir a luz, numa contundente afirmação da sua presença no imaginário que envolve a obra. Apollo responde: "No sol e nas estrelas | reconhecerás seu belo semblante". (STRIGGIO, 2011, p. 40, tradução nossa) ${ }^{52}$ A tradução pode ter se rendido à relevância da luz ou pode ter acrescentado o termo para garantir maior expressão e empatia. Em ambos os casos, isso se deve à reconhecida importância da luz, uma vez que, sem ela, ambiente e atmosfera seriam inexistentes na práxis cênica.

Configura-se, então, mais um exemplo de acontecimento artístico no qual a ação humana é representada, discutida e/ou interpretada em cena. Elabora-se um ambiente que abriga embates provocados por desejos humanos, estabelecendo uma manifestação artística cujo processo incorpora a luz desde os primeiros passos. O que se modifica é a natureza de cada obra, o pensamento que a suporta ou provoca. A compreensão da práxis cênica grega da Antiguidade, como uma manifestação permeada pela expressão musical, apontou para uma representação encarada como drama, no qual a palavra é cantada e até pontuada com diálogos e narrativa. Com Orfeu, A Camerata florentina dé Bardi inaugura, então, um tratamento espacial da cena, que resulta numa visualidade específica.

Do ponto de vista da música, o tempo de Monteverdi está localizado na primeira década do século XVII, na transição entre o pensamento renascentista e as emoções, a incorporação de grandeza e o movimento, do Barroco. Se alguns estudiosos registram o ano 1600 - com a ópera Eurídice, de Jacopo Peri - como o início do Barroco na música, sabe-se que a expressão artística, cuja denominação se origina no termo português que se refere a uma pérola deformada, ganhou abrangência, incorporando outras formas de arte. As artes visuais, a arquitetura, a

51 "Sì non vedrò più mai | de l'amata Euridice i dolci rai?"
52 “Nel sole e nelle stelle | vagheggerai le sue sembianze belle." 
pintura, a escultura e as artes cênicas incorporaram tal mentalidade, que se originou na Itália e logo avançou por toda a Europa.

A ópera barroca configurou-se sob o fascínio da simbiose de todas as artes numa única obra. Era uma fantasia utópica, contida no legado do Renascimento que o Barroco levou ao que se acreditava uma concretização triunfal. 